\title{
Neurotrophin receptor activation rescues cognitive and synaptic abnormalities caused by hemizygosity of the psychiatric risk gene Cacna1c
}

\author{
Cezar M. Tigaret ${ }^{1} \cdot$ Tzu$^{-C h i n g ~ E . ~ L i n ~}{ }^{1} \cdot$ Edward R. Morrell ${ }^{2,3} \cdot$ Lucy Sykes $^{1,6} \cdot$ Anna L. Moon $^{1,4} \cdot$ \\ Michael C. O'Donovan $\mathbb{1}^{1,4} \cdot$ Michael J. Owen $\mathbb{1}^{1,4} \cdot$ Lawrence S. Wilkinson ${ }^{1,2,4} \cdot$ Matthew W. Jones $\mathbb{1}^{3} \cdot$ \\ Kerrie L. Thomas ${ }^{1,5} \cdot$ Jeremy Hall $\mathbb{1}^{1,4}$
}

Received: 17 June 2020 / Revised: 2 December 2020 / Accepted: 10 December 2020 / Published online: 17 February 2021

(c) The Author(s) 2021. This article is published with open access

\begin{abstract}
Genetic variation in $C A C N A 1 C$, which encodes the alpha- 1 subunit of $\mathrm{Ca}_{\mathrm{V}} 1.2 \mathrm{~L}$-type voltage-gated calcium channels, is strongly linked to risk for psychiatric disorders including schizophrenia and bipolar disorder. To translate genetics to neurobiological mechanisms and rational therapeutic targets, we investigated the impact of mutations of one copy of Cacnalc on rat cognitive, synaptic and circuit phenotypes implicated by patient studies. We show that rats hemizygous for Cacnalc harbour marked impairments in learning to disregard non-salient stimuli, a behavioural change previously associated with psychosis. This behavioural deficit is accompanied by dys-coordinated network oscillations during learning, pathway-selective disruption of hippocampal synaptic plasticity, attenuated $\mathrm{Ca}^{2+}$ signalling in dendritic spines and decreased signalling through the Extracellular-signal Regulated Kinase (ERK) pathway. Activation of the ERK pathway by a small-molecule agonist of TrkB/TrkC neurotrophin receptors rescued both behavioural and synaptic plasticity deficits in $\mathrm{Cacnalc}^{+/-}$rats. These results map a route through which genetic variation in CACNAIC can disrupt experience-dependent synaptic signalling and circuit activity, culminating in cognitive alterations associated with psychiatric disorders. Our findings highlight targeted activation of neurotrophin signalling pathways with BDNF mimetic drugs as a genetically informed therapeutic approach for rescuing behavioural abnormalities in psychiatric disorder.
\end{abstract}

These authors contributed equally: Cezar M. Tigaret, TzuChing E. Lin

These authors jointly supervised this work: Kerrie L. Thomas, Jeremy Hall

Supplementary information The online version contains supplementary material available at https://doi.org/10.1038/s41380020-01001-0.

Jeremy Hall

hallj10@ cardiff.ac.uk

1 Neuroscience and Mental Health Research Institute, Division of Psychological Medicine and Clinical Neurosciences, School of Medicine, Cardiff University, Cardiff, UK

2 School of Psychology, Cardiff University, Cardiff, UK

3 School of Physiology, Pharmacology and Neuroscience, University of Bristol, Bristol, UK

\section{Introduction}

The major psychiatric disorders such as schizophrenia and bipolar disorder place an enormous burden on society yet have seen little advances in mechanistic understanding and therapy. While schizophrenia and bipolar disorder can present differently in the clinic, both are associated with psychosis and they have significantly shared genetic architecture [1]. Recent advances in the understanding of the genomic basis of these conditions

4 MRC Centre for Neuropsychiatric Genetics and Genomics, Division of Psychological Medicine and Clinical NeurosciencesSchool of Medicine, Cardiff University, Cardiff, UK

5 School of Bioscience, Cardiff University, Cardiff, UK

6 Present address: Neem Biotech, Abertillery, Blaenau Gwent, UK 
may pave the way to new therapeutics [2]. Particularly promising in this respect is the demonstration of strong associations of both schizophrenia and bipolar disorder with genetic variations in voltage-gated calcium channels (VGCCs) [3], especially the CACNAIC gene, which encodes the pore-forming $\alpha_{1 C}$ subunit of $\mathrm{Ca}_{\mathrm{V}} 1.2 \mathrm{~L}$-type VGCCs (L-VGCCs) $[4,5]$.

The exact molecular effects of the CACNAIC riskassociated single nucleotide polymorphisms (SNPs) are not fully understood. Common risk SNPs in CACNAIC are intronic and likely to alter $C A C N A I C$ gene expression, with decreased expression seen in some, but not all, studies [6-10]. Recent evidence suggests that in human hippocampus the risk SNPs act to reduce CACNA1C expression [10]. The association of rare deleterious mutations in genes encoding VGCC subunits, including CACNA1C, with schizophrenia and other neurodevelopmental disorders further supports the view that decreased CACNAIC expression can contribute to disease risk $[11,12]$. Understanding the functional effects of $C A C$ NAIC dosage, and in particular reduced dosage, is therefore necessary to discerning the contribution of genetic variation in L-VGCCs to neuropsychiatric risk.

$\mathrm{Ca}_{\mathrm{V}} 1.2 \mathrm{~L}-\mathrm{VGCCs}$ are highly expressed in the mammalian brain, including hippocampus [13]. Clinical and preclinical studies implicate hippocampal abnormalities in the pathophysiology of schizophrenia and bipolar disorder [14-16], and impaired hippocampus-dependent associative learning in the development of psychosis [17-20]. Hippocampal associative learning is orchestrated by rhythmic neural activity in the entorhinal-hippocampal network $[21,22]$ and is underpinned by associative synaptic plasticity at glutamatergic synapses, induced by coordinated activation of postsynaptic NMDA receptors (NMDAR) and VGCCs including L-VGCCs [23-26].

At a molecular level L-VGCCs link membrane depolarization to transcription via the Extracellular-signal Regulated Kinase (ERK) signalling pathway which regulates synaptic plasticity [27-30] and activates transcription factors including CREB controlling the expression of genes required for long-term plasticity [29, 30]. Thus, L-VGCC-mediated calcium signalling regulates the changes in synaptic efficacy and gene expression underlying associative learning.

In this study we used a Cacnalc ${ }^{+/-}$rat model [31] in order to examine the impact of reduced Cacnalc dosage on hippocampal associative learning, synaptic plasticity, circuit activity and ERK signalling. Having mapped the mechanistic links between genetic variation in Cacnalc and behavioural phenotype we showed that activation of ERK signalling with a small-molecule TrkB/TrkC neurotrophin receptor agonist could rescue the behavioural and synaptic plasticity impairments.

\section{Materials and methods}

\section{Animals}

Cacnalc $^{+/-}$rats [31] with a truncating mutation in exon 6 of Cacnalc gene were generated from cryo-preserved embryos (strain SD-Cacnalc ${ }^{\text {tmlSage }}$, Sage Research Labs, Pennsylvania, USA) and bred at Charles River (Margate, UK), Cardiff and Bristol Universities. We used 278 Cacnalc $^{+/+}$and heterozygous littermates, and 54 male Lister Hooded rats (Charles River, UK) for behavioural experiments using intrahippocampal diltiazem (DTZ) infusion. Littermates were housed up to four per cage, with access to food and water ad libitum. Experiments were performed on mature animals (age: 12-52 weeks) [32] maintained under normal $(12 \mathrm{~h} / 12 \mathrm{~h})$ or reversed light/dark cycle (dark: 10 a.m. to 8 p.m. for behavioural studies; behavioural training at 11 a.m.). Animal handling followed Home Office regulations as directed by Home Office Licensing teams at the host institutions.

\section{Behavioural, electrophysiological, and molecular methods}

These procedures are described in Supplementary Materials and methods.

\section{Statistical analysis}

Sample sizes were determined as described in Supplementary Materials. Animals were assigned pseudo-randomly to experimental groups, with experiments performed blind to genotype. Specific statistical analyses are given in Supplementary Materials and methods. Pooled data are represented as mean $\pm \mathrm{SEM}$. Asterisks show statistical significance: $* p<0.05 ; * * p<0.01 ; * * * p<0.001$.

\section{Results}

\section{Cacna1c hemizygosity disrupts latent inhibition of contextual fear conditioning}

We investigated the effects of reduced $\mathrm{Ca}_{\mathrm{V}} 1.2$ dosage on associative fear learning using rats hemizygous for a truncating mutation in exon 6 of Cacnalc gene encoding the pore-forming $\alpha_{1 \mathrm{C}}$ subunit of $\mathrm{Ca}_{\mathrm{V}} 1.2$ L-VGCCs [33] ("Materials and methods"). Cacnalc $^{+-}$rats have an approximately $50 \%$ decrease in hippocampal Cacnalc mRNA and protein [31]. We assessed the behavioural impact of $\mathrm{Cacnalc}^{+/-}$hemizygosity by testing contextual fear conditioning (CFC) in Cacnalc ${ }^{+/-}$and wild-type littermates, a hippocampal-dependent behavioural response 

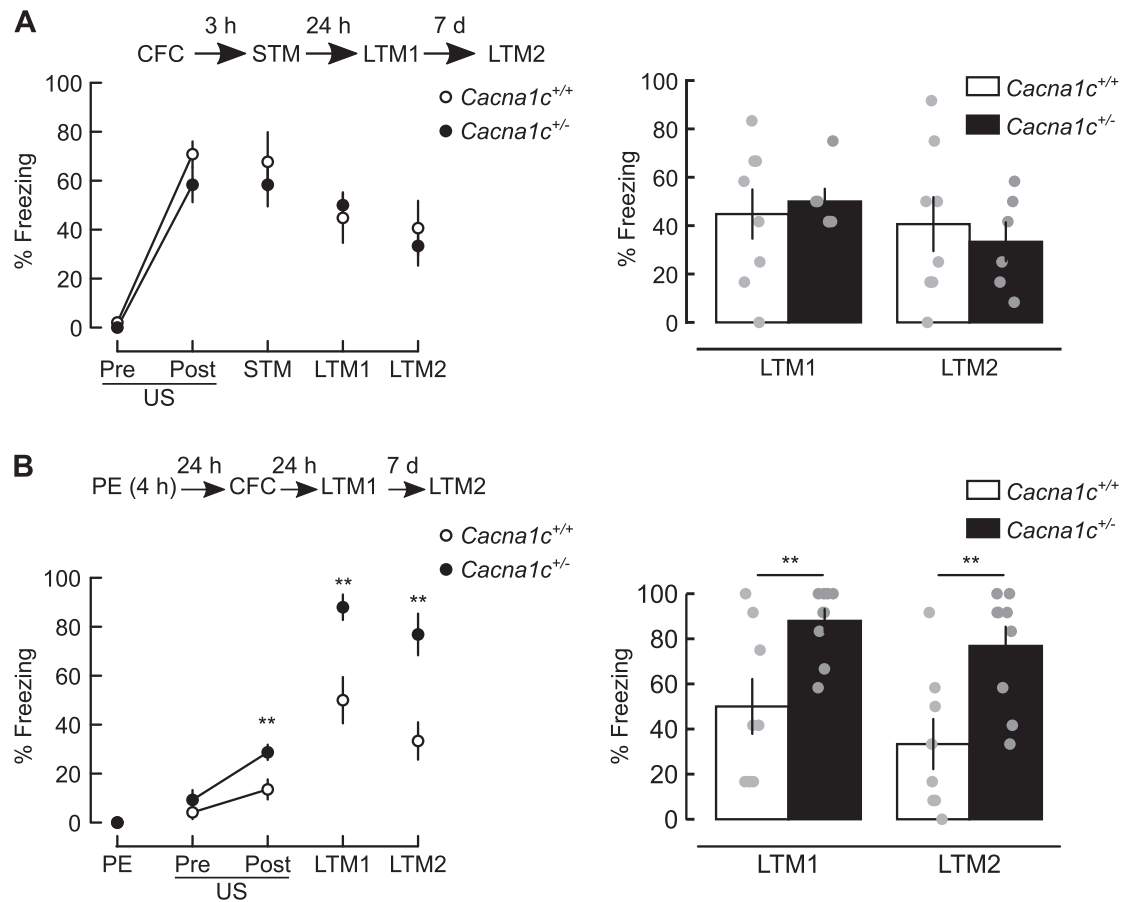

Fig. 1 Low Cacnalc dosage selectively impairs latent inhibition (LI) of contextual fear memory CFM. All panels: Left: schematics of behavioural protocols (top) and freezing responses measured during all trials (bottom). PE: $4 \mathrm{~h}$ context pre-exposure; CFC contextual fear conditioning comprising Pre-US and Post-US epochs before and after footshock (US), respectively; STM, LTM1, LTM2: short-term and long-term contextual fear memory (CFM) retrieval trials. Right: Summary of freezing responses at LTM tests. A Acquisition and consolidation of CFC are unaltered in $\mathrm{Cacnalc}^{+/-}$animals. Effects of genotype: $F_{(1,12)}=0.385, p=0.546$, trial: $F_{(4,48)}=29.624, p<0.001$;

that requires L-VGCC activation [34, 35]. During training animals received a single mild footshock (US, $2 \mathrm{~s}, 0.5 \mathrm{~mA}$ ) 2 min after being placed in a novel context (Fig. 1A and Supplementary Methods). Context-fear association memory was assessed by measuring the freezing response upon return to the conditioned context $3 \mathrm{~h}$ (short-term memory, STM), $24 \mathrm{~h}$ (long-term memory, LTM1), and 8 days (LTM2) after CFC training. Cacnalc ${ }^{+/+}$and Cacnalc $^{+/-}$ animals had equivalent levels of fear response throughout training and recall sessions (Figs. 1A and S1), indicating that reduced dosage of Cacnalc did not alter contextual fear learning per se.

We next assessed the performance of Cacnalc ${ }^{+/-}$and Cacnalc $^{+/+}$littermates in a paradigm of latent inhibition (LI) of CFC (schematics in Figs. 1B, S1A). LI is the reduced ability to form conditioned associations to a stimulus (here, the conditioning context) due to pre-exposure to stimulus alone and reflects learning to ignore irrelevant stimuli, which is impaired in psychosis [17, 18, 36]. Animals were pre-exposed to the to-be-conditioned context (PE) for $4 \mathrm{~h}$, then trained for CFC $24 \mathrm{~h}$ or $48 \mathrm{~h}$ later (Figs. 1B, S1). Pre-exposure produced a robust LI of CFC genotype $\times$ trial interaction: $F_{(4,48)}=0.533, p=0.712 ;$ Cacnalc $^{+/-}$: $n=6$; Cacnalc $^{+/+}: n=8$. B Higher levels of freezing post-US and during CFM retrieval trials indicate the Cacnalc $^{+/-}$animals have a deficit in the LI. Genotype $\times$ session interaction: $F_{(2.1,31.49)}=6.119$, $p=0.005$; pairwise comparisons between genotypes: Post-US: $F_{(2.1,31.47)}=10.464, p=0.006$; LTM1: $F_{(2.1,31.49)}=8.895, p=0.009$; LTM2: $F_{(2.1,31.49)}=9.869, p=0.007$ (Greenhouse-Geisser corrected); Cacnalc $^{+/-}: n=9 ;$ Cacnalc $^{+/+}: n=8$. Data presented as means \pm SEM. $* * p<0.01$ determined by two-way repeated measures ANOVA followed by pairwise post-hoc comparison with Bonferroni correction.

in Cacnalc $^{+/+}$animals, manifested as reduced freezing response at LTM trials, but not in Cacnalc $^{+/-}$littermates (Figs. 1B, S1 comparing pre-exposed and non-pre-exposed animals). Therefore, Cacnalc hemizygosity selectively impaired LI of CFC. In wild-type animals LI of CFC was disrupted by infusion of L-VGCC antagonist DTZ in dorsal hippocampus during pre-exposure (Fig. S2). Together, these results demonstrate a specific role for hippocampal $\mathrm{Ca}_{\mathrm{V}} 1.2$ channels during the pre-exposure stage in LI of CFC paradigm. We therefore focussed our further physiological studies on the hippocampus.

LI of CFC requires dorsal hippocampal-dependent formation of context-specific memories [37]. We hypothesized that the LI of CFC deficit in Cacnalc $^{+/-}$animals reflects a disruption of dorsal hippocampal processes that encode novel environment representations during pre-exposure. Therefore, we investigated the impact of Cacnalc hemizygosity on two fundamental hippocampal mechanisms proposed to support memory encoding: associative plasticity at CA1 pyramidal cell synapses [23] and phase-amplitude coupling (PAC) between the theta and gamma oscillations of the local field potential (LFP) in CA1 [21]. 
A

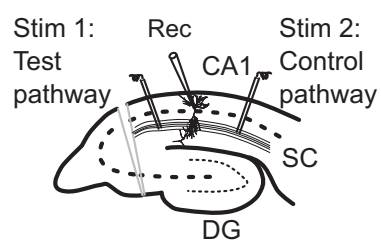

B

B $\quad$ Cacna1c $c^{+/}$

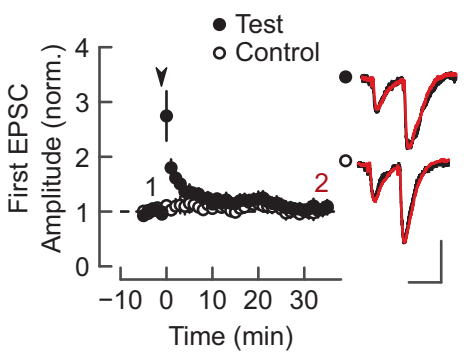

E

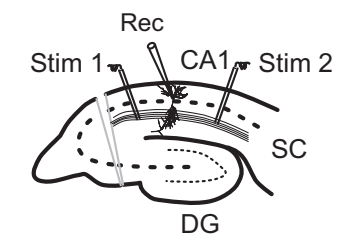

F

Cacna1c $\mathrm{C}^{+/-}$

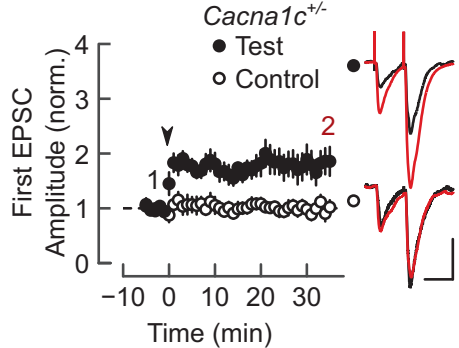

I

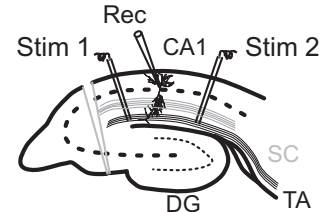

C

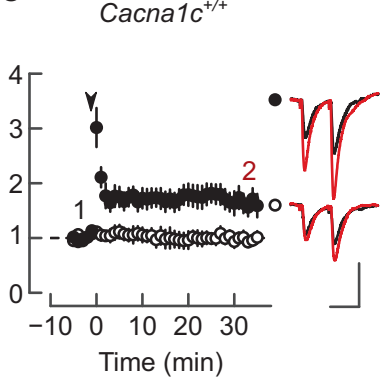

Theta-burst pairing (TBP)

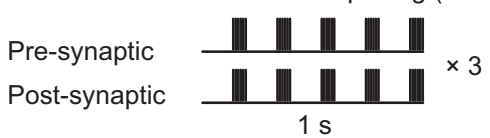

D

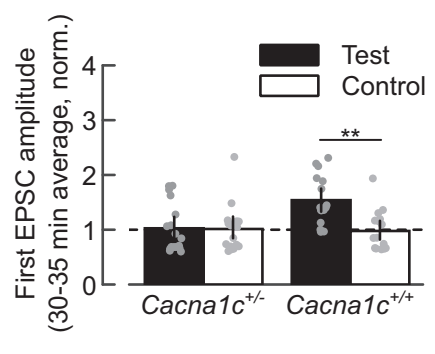
\begin{tabular}{lr} 
Pre-synaptic & \multicolumn{2}{c}{ LFS Pairing } \\
Post-synaptic & $0 \mathrm{mV}$ \\
$-70 \mathrm{mV}$ & $\frac{1}{1 \mathrm{~s}} \times 90$
\end{tabular}

G

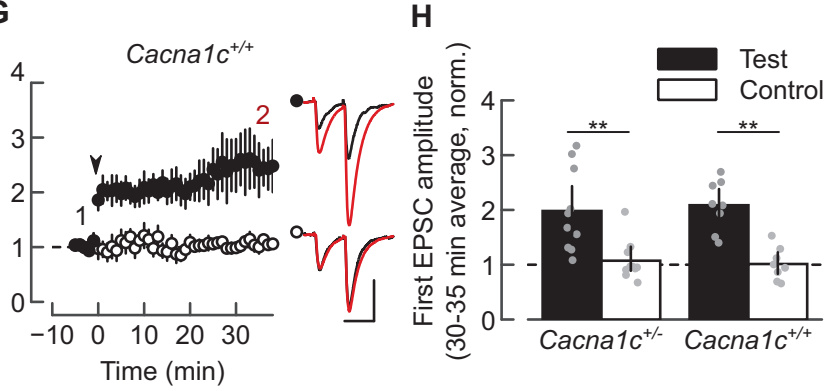

$\mathrm{H}$ 
Fig. 2 Reduced Cacnalc dosage impairs LTCC-sensitive induction of associative LTP selectively at Schaffer collateral to CA1 (SCCA1) synapses. A Electrodes placements (left) and theta-burst pairing (TBP) protocol (right) for LTP at SC-CA1 synapses. B No TBP-induced LTP at SC-CA1 synapses in Cacnalc ${ }^{+/-}$slices. C TBP-induced robust homosynaptic LTP at SC-CA1 in Cacnalc ${ }^{+/+}$ slices. D Summary of normalized change in EPSC amplitude at 30-35 min shown in (B) and (C). Effect of genotype on LTP: $\mathbf{L R}_{(1)}$ $=5.16, p=0.023$; genotype $\times$ pathway interaction: $\mathrm{LR}_{(1)}=7, p=$ 0.0081. Pairwise comparisons of Test vs Control pathway for Cac$n a 1 c^{+/-}: p=0.99, n=17$ (12: 4 females and 8 males); Cacnalc $^{+/+}$: $p=0.0057, n=16(9)$. E Electrodes placements (left) and lowfrequency stimulation (LFS-pairing) protocol (right) for SC-CA1 LTP. LFS-pairing induces SC-CA1 LTP in Cacnalc $^{+/-}(\mathbf{F})$ and Cacnalc $^{+/+}$slices (G). H Summary of EPSC amplitude change at 30-35 min shown in $(\mathbf{F})$ and $(\mathbf{G})$ : no effect of genotype $\left(\operatorname{LR}_{(1)}=\right.$ $0.103, p=0.748)$ or genotype $\times$ pathway interaction $\left(\mathrm{LR}_{(1)}=0.227\right.$, $p=0.633)$ on LTP. Pairwise Test vs Control for Cacnalc ${ }^{+/-}: p=$ $0.0027, n=10(7)$; Cacnal $^{+/+}: p=0.0011, n=8(6)$. I Electrode placements (left) and TBP protocol (right) for LTP at TA-CA1 synapses. TBP induces homosynaptic TA-CA1 LTP in slices from Cacnalc $^{+/-}(\mathbf{J})$ and Cacnalc ${ }^{+/+}$animals (K). L Summary of changes in normalized EPSC amplitude at 30-35 min shown in (F) and $(\mathbf{G})$ : no effect of genotype $\left(\mathrm{LR}_{(1)}=0.0258, p=0.8724\right)$ and no genotype $\times$ pathway interaction $\left(\mathrm{LR}_{(1)}=0.065, p=0.798\right)$; contrast Test versus Control pathways, in Cacnalc ${ }^{+/-}: p=0.0093, n=8(7)$; Cacnalc $^{+/+}: p=0.014, n=7(5)$. Plots show EPSC amplitude timecourse in Test and Control pathways, normalized to 5 min average before LTP induction (arrowheads). Insets: $5 \mathrm{~min}$ average EPSC waveforms before (1, black) and 30-35 min after (2, red) LTP induction; scale bars: $50 \mathrm{pA}, 50 \mathrm{~ms}$. Sample sizes given as cells (animals-all males unless indicated). Data presented as means \pm SEM. $* p<0.05, * * p<0.01$ determined by two-way ordinal regression (cumulative link model) followed by analysis of deviance (ANODE) (colour figure online).

action potentials (APs) (Fig. 2A). TBP mimics theta-burst firing patterns observed in vivo during learning and exploration of novel environments [40, 42, 43] and induces LTP (TBPLTP) through coordinated activation of postsynaptic NMDAR and VGCCs [26, 44]. TBP failed to induce SC-CA1 LTP in Cacnalc $^{+/-}$animals (Fig. 2B, D). This deficit was present in male and female $\mathrm{Cacnalc}^{+-}$animals (Fig. S3), therefore subsequent experiments were performed in males. In Cacnalc $^{+/+}$slices TBP produced robust SC-CA1 LTP (Fig. 2C, D) which was blocked by L-VGCC antagonists isradipine, DTZ, and the NMDAR antagonist L-689560 (Fig. S4A-C, H), confirming NMDAR and L-VGCC requirements for TBP-LTP.

To discern whether non-specific impairments of postsynaptic mechanisms caused the failure of SC-CA1 LTP in $\mathrm{Cacnalc}^{+/-}$animals, we tested an alternative LTP induction by pairing low-frequency synaptic stimulation with tonic postsynaptic depolarization (LFS-pairing, Fig. 2E). LFS-pairing generates NMDAR-dependent LTP without postsynaptic APs or L-VGCC contribution [45]. LFS-pairing induced robust SC-CA1 LTP in both genotypes (Fig. 2F-H), which was insensitive to L-VGCC antagonists but was blocked by L-689560 (Fig. S4D-F, $\mathrm{H})$ confirming the dependency of LFS-pairing LTP on NMDARs but not L-VGCCs. In contrast, TA-CA1 synapses exhibited robust TBP-LTP in both genotypes (Fig. 2I-L) which was sensitive to L-VGCC block in wild-type slices (Fig. S4G, H). Paired-pulse facilitation was similar between genotypes (Fig. S5) indicating unaltered neurotransmitter release.

These results show that Cacnalc hemizygosity selectively impairs forms of LTP that require L-VGCC activation during postsynaptic AP bursts, without affecting NMDARdependent mechanisms, at the SC-CA1 pathway.

\section{Cacna1c $^{+/-}$CA1 pyramidal neurons have impaired spine $\mathrm{Ca}^{2+}$ signalling during postsynaptic spike bursts}

Cacnalc $^{+/-}$CA1 pyramidal neurons had a small reduction in isradipine-sensitive whole-cell calcium currents (Fig. S6) measured using a voltage-ramp method [24] (Supplementary Methods). We hypothesized that the observed neurophysiological deficits arise from local alterations in $\mathrm{Ca}_{\mathrm{V}} 1.2$ availability for processes such as AP repolarization and spine $\mathrm{Ca}^{2+}$ signalling, which we investigated next. Neurons from both genotypes had comparable passive membrane properties, AP threshold and rheobase current (Supplementary Table S1, Fig. S7A-E). However, somatic AP broadening during highfrequency $(>40 \mathrm{~Hz})$ firing was significantly reduced in $\mathrm{Cac}$ nalc ${ }^{+/-}$neurons compared to wild-type cells (Fig. S7F-I). Somatic AP broadening occurs normally during AP bursts, mediated by voltage- and $\mathrm{Ca}^{2+}$-sensitive $\mathrm{K}^{+}$channel complexes [46, 47] which can associate $\mathrm{Ca}_{\mathrm{v}} 1.2$ L-VGCCs $[48,49]$. In Cacnalc $^{+/+}$neurons isradipine lowered somatic AP broadening to levels comparable to those in $\mathrm{Cacnalc}^{+/-}$ neurons in the absence of drug (Fig. S7J, K). Therefore, low $\mathrm{Ca}_{\mathrm{V}} 1.2$ dosage appears to alter $\mathrm{Ca}^{2+}$-sensitive spike repolarization during burst firing.

AP broadening in CA1 pyramidal neurons is thought to facilitate dendritic backpropagation of somatic spikes [50] necessary for associative synaptic plasticity such as TBPLTP $[26,44]$ and amplification of $\mathrm{Ca}^{2+}$ signals during AP bursts [47]. $\mathrm{Ca}_{\mathrm{V}} 1.2 \mathrm{~L}-\mathrm{VGCCs}$ are expressed in dendrites and dendritic spines [51, 52], and are activated by backpropagated APs [26, 51]. The impaired AP broadening during burst firing in Cacnalc $^{+-}$neurons may impact plasticity induction by altering dendritic spine $\mathrm{Ca}^{2+}$ signals triggered by backpropagated APs. We tested this hypothesis by analyzing $\mathrm{Ca}^{2+}$ transients elicited with AP bursts (APCaTs) in spines of radial oblique dendrites (Figs. 3A, B and S8, Supplementary Tables S2 and S3). APCaTs attenuated with increasing distance from soma (Figs. 3C-E and S9). Compared to wild-type cells, the APCaTs in spines at $150-250 \mu \mathrm{m}$ from soma in Cacnalc $^{+/-}$neurons were 
A

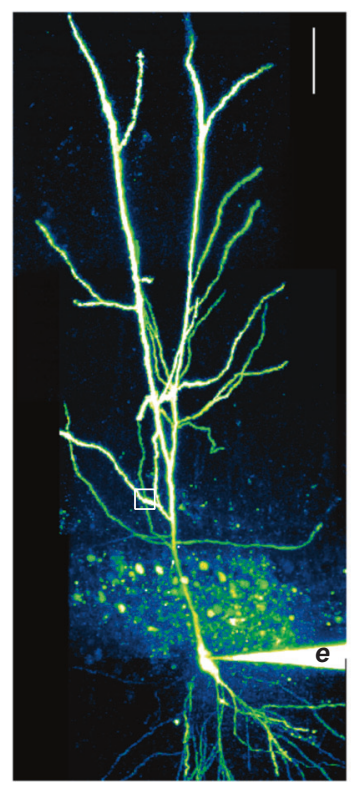

B
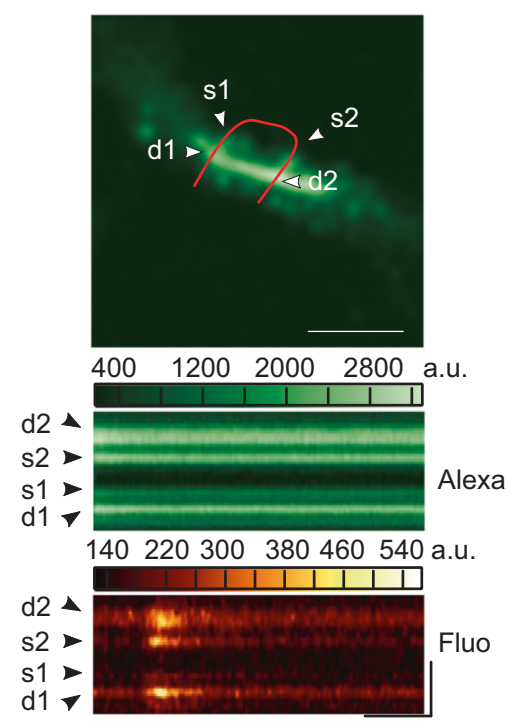

$5 \mathrm{AP}, 100 \mathrm{~Hz}$
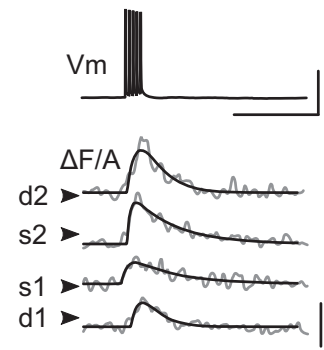

C

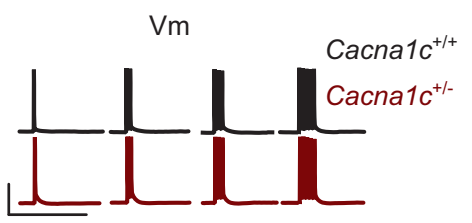

Distance from soma: $<150 \mu \mathrm{m}$

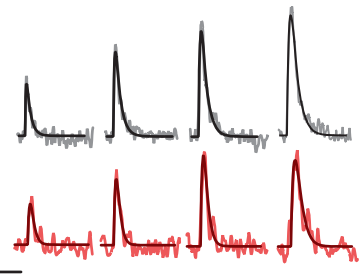

$150-250 \mu \mathrm{m}$

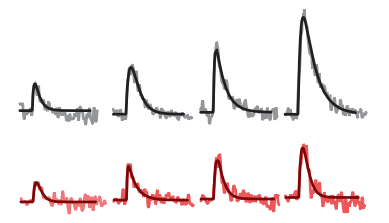

$\Lambda_{1}^{250-400 \mu \mathrm{m}}$

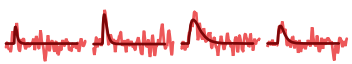

D

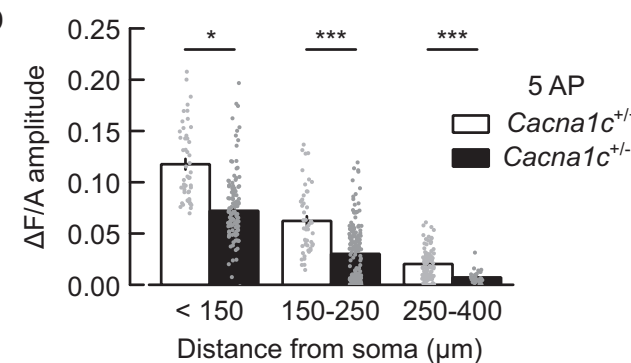

$\mathbf{F}$

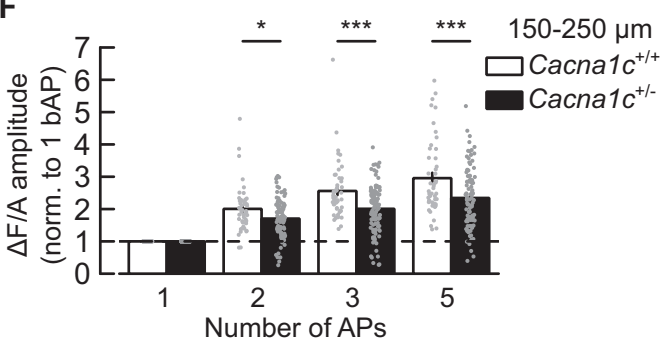

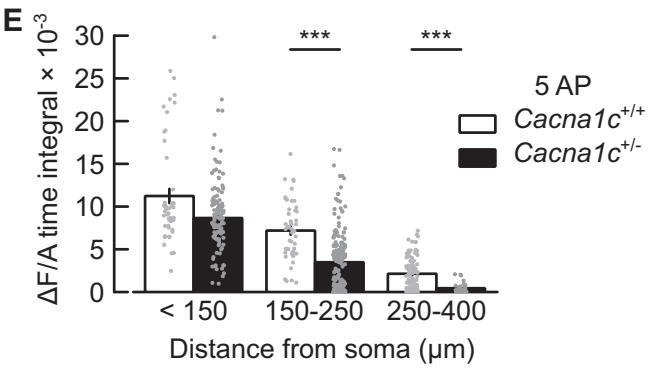

G

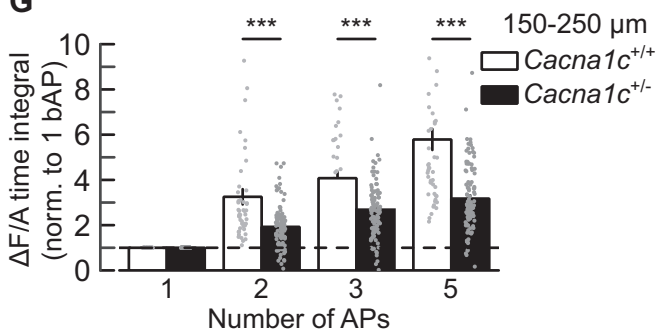

$\mathrm{Cacna1c}^{+/-}$animals have reduced PhaseAmplitude Coupling between theta and gamma oscillations of dorsal CA1 LFP

The establishment of neuronal ensembles involved in novel environment encoding depends on the synchronization of consistently smaller (Fig. 3D, E) and scaled poorly with AP burst size (Figs. 3F, G and S10).

These results show that low Cacnalc dosage in CA1 pyramidal neurons alters AP-associated spine $\mathrm{Ca}^{2+}$ signalling at SC-CA1 synapses, which may underlie the observed selective deficit in synaptic plasticity. 
Fig. 3 Low Cacnalc dosage is correlated with a reduction of spine $\mathrm{Ca}^{2+}$ signals elicited by backpropagated action potentials in CA1 pyramidal cells. A CA1 pyramidal neuron during spine $\mathrm{Ca}^{2+}$ imaging (Z-projected pseudo-colour image, Alexa Fluor 594 channel; white square: spine imaging region; $e$ : recording electrode; scale: $50 \mu \mathrm{m})$. B Imaging of spine $\mathrm{Ca}^{2+}$ transients elicited by backpropagated action potentials (APCaTs). Top-to-bottom: imaging region in (A) with spines (s1, s2), parent dendrite (d1, d2) and line-scan trajectory (red); line-scan images, Alexa Fluor 594 (Alexa) and Fluo 5F (Fluo) channels, during five somatic APs (Vm); APCaTs during the 5 APs (grey: $\Delta F / A$, change in fluorescence intensity in Fluo channel, relative to Alexa channel; black: double-exponential fit). Scales, vertical: $2 \mu \mathrm{m}$, $20 \mathrm{mV}, 0.1$ arbitrary units (a.u.); horizontal: $0.2 \mathrm{~s}$. C Example APCAT waveforms elicited by $1-5$ somatic AP $(\mathrm{Vm})$ in spines within three distance zones. Scale: $20 \mathrm{mV}, 0.02$ a.u., $0.2 \mathrm{~s}$. APCaTs have smaller amplitude (D) and time integral (E) in Cacnalc ${ }^{+/-}$versus Cacnalc $^{+/+}$ neurons (pairwise comparisons of 5 AP APCaTs, in distance zones $(\mu \mathrm{m})<150$ : amplitude $p=0.0473$, time integral $p=0.414 ; 150-250$ : both measures $p<0.0001 ; 250-400$ : both measures $p<0.0001)$. F, G Summation of APCaT amplitude $(\mathbf{F})$ and time integral $(\mathbf{G})$ with the number of APs is reduced in Cacnalc ${ }^{+/-}$versus Cacnalc ${ }^{+/+}$ neurons (pairwise comparisons for APCaTs at $150-250 \mu \mathrm{m}$, for 2 AP: normalized amplitude $p=0.15$, normalized time integral $p<0.0001,3$ AP: both measures $p<0.0001 ; 5$ AP: both measures $p<0.0001$ ). Data were expressed as means \pm SEM. $* p<0.05, * * p<0.01$ and $* * * p<$ 0.001 determined by two-way repeated measures ANOVA followed by Tukey adjustment of $p$ values for contrasts. Statistical analysis results and sample sizes are given in Supplementary Table S2 and Fig. S8; all $p$ values for pairwise comparisons are given in Supplementary Table S3 (colour figure online).

excitatory inputs in the CA1 subfield, facilitating synaptic plasticity [21, 53, 54]. To determine the impact of Cacnalc heterozygosity on dorsal CA1 network synchronization, we monitored the modulation of LFP gamma oscillations by the phase of LFP theta oscillations (theta-gamma PhaseAmplitude Coupling, PAC). Hippocampal theta-gamma PAC is a proposed mechanism for storage and recall of object and event representations $[22,55,56]$. The slow $(\sim 25-40 \mathrm{~Hz})$ and fast $(\sim 65-140 \mathrm{~Hz})$ gamma oscillations in dorsal CA1 reflect the synchronization between pyramidal neurons in CA1 with neurons in CA3 (via SC-CA1 pathway) and entorhinal cortex (EC) (via TA-CA1 pathway) [57].

To determine the changes in theta-gamma PAC during the exploration of a novel environment we recorded dorsal CA1 LFP oscillations in rats running along a track in a familiar, then a novel environment (Figs. 4A and S11A-C). This approach accounts for correlations of hippocampal theta and gamma rhythms and their coupling with movement [58-60]. In the familiar environment, animals from both genotypes had similar PAC across the gamma frequency spectrum (Fig. 4B, C, "Familiar" sub-panels) and power spectra of LFP oscillations in the $1-40 \mathrm{~Hz}$ range (Fig. S11D, E). Upon switching to novel environment, the PAC levels in Cacnalc $^{+/+}$were similar to the initial response to the subsequently familiar environment (Fig. 4B,
C, "Novel" sub-panels). Cacnalc ${ }^{+/-}$animals had significantly impaired theta-gamma PAC response (Fig. 4B, C) in the novel environment, unrelated to behavioural response to novelty (Fig. S12). Our results reveal a CA3-CA1 network mis-coupling in Cacnalc $^{+/-}$animals, which may further disrupt hippocampal encoding of contextual information and contribute to the observed LI deficit.

\section{A TrkB/TrkC agonist rescues synaptic plasticity and behavioural deficits in $\mathrm{Cacna1c}^{+/-}$animals}

We next investigated molecular changes associated with altered hippocampal synaptic plasticity and network activity in Cacnalc $^{+/-}$animals. The deficit in AP-elicited spine $\mathrm{Ca}^{2+}$ signals in $\mathrm{Cacnalc}^{+/-}$rats may impact on $\mathrm{Ca}^{2+}$-dependent ERK signalling, which couples $\mathrm{Ca}_{\mathrm{V}} 1.2 \mathrm{~L}-\mathrm{VGCCs}$ activation to synaptic plasticity $[27,28]$ and CREB-regulated gene expression for long-term memory [29, 30]. Phosphorylated ERK (pERK, Fig. 5A) and CREB (pCREB, Fig. 5B) immunoreactivities were significantly reduced in Cacnalc $^{+/-}$ dorsal hippocampus. A separate cohort replicated these findings (Fig. S13A, C) without genotype effect on total ERK and CREB levels (Fig. S13B, D). We detected no differences in hippocampal morphology and cellular density between genotypes (Fig. S14). These results indicate impaired ERK- and CREB-mediated synapse-to-nucleus signalling in $\mathrm{Cacnalc}^{+/-}$ rats, that may contribute to the observed behavioural and hippocampal dysfunctions. We tested this hypothesis by directly activating ERK signalling using a recently characterized small-molecule TrkB/TrkC neurotrophin receptor co-activator LM22B-10 with brain-derived neurotrophic factor (BDNF) mimetic properties including ERK activation in neurons [61]. Systemic administration of LM22B-10 in Cacnalc $^{+/-}$rats $(25 \mathrm{mg} / \mathrm{kg}$ i.p., yielding micromolar concentrations in the brain [61]) restored the baseline levels of pERK and pCREB 60 min after injection (Figs. 5A, B and S15) without significant effect in wild-type littermates. We next determined whether LM22B-10 could rescue hippocampal synaptic plasticity in Cacnalc $^{+-}$rats. LM22B-10 rescued TBP-LTP at SC-CA1 synapses in Cacnalc $^{+/-}$slices, either during bath-application in vitro (Fig. $5 \mathrm{C}, \mathrm{G}$ ) or in slices prepared $60 \mathrm{~min}$ after intra-peritoneal administration (Fig. 5E, G), without effect in Cacnalc ${ }^{+/+}$littermates (Fig. 5D, F, G). Thus, activation of TrkB/TrkC receptors with local or systemic administration of a BDNF mimetic drug bypasses $\mathrm{Ca}_{\mathrm{V}} 1.2$ L-type VGCC signalling to rescue ERK signalling and associative hippocampal plasticity in $\mathrm{Cacnalc}^{+/-}$rats.

The reversal of molecular and synaptic plasticity deficits in Cacnalc $^{+/-}$rats with LM22B-10 prompted us to investigate whether activation of hippocampal TrkB/TrkC receptors could rescue the observed deficit in LI of CFC. A single intra-dorsal hippocampal administration of 
Fig. 4 Reduced theta-slowgamma coupling in a novel environment in Cacnalc $^{+/-}$ rats. A Local field potentials taken from runs on the familiar track. Top: Representative broadband LFP traces $(0.1-475$ $\mathrm{Hz}$ ) taken from dorsal CA1 in a $5 \mathrm{~s}$ window while running. Bottom: $1 \mathrm{~s}$ expanded segment showing raw unfiltered LFP (top) and bandpass filtered theta (6-10 Hz), slow gamma (25-55 $\mathrm{Hz})$ and fast gamma (60-140 $\mathrm{Hz}$ ) (bottom). Phase-amplitude coupling measures the degree to which the amplitude envelope (blue traces shown for slow and fast gamma) is modulated by the phase signal (theta filtered LFP). Black: Cacnalc ${ }^{+/+}$; red: Cacnac1 $^{+/-}$; dashed vertical lines mark timings of theta cycle peaks. B Mean phase-amplitude coupling comodulograms taken from track runs on the familiar and novel track. Colour represents the modulation index (MI) depicting the degree of coupling between the phase of frequencies $(1-20 \mathrm{~Hz})$ on the $x$-axis and the amplitude of frequencies $(1-200 \mathrm{~Hz})$ on the $y$-axis. Differences between environments and genotypes are shown next to the mean plots as labelled (Cacnalc ${ }^{+/+}: n=5$; Cacnalc $\left.^{+/-}: n=7\right)$. C Mean phase-amplitude coupling between theta $(6-10 \mathrm{~Hz})$ and slow gamma $(25-55 \mathrm{~Hz})$. Theta-slow gamma coupling was lower in Cacnalc ${ }^{+-}$rats than Cacnalc $^{+/+}$rats on the novel track $(p=0.0256)$ but not on the familiar track ( $p=$ 0.9184). Cacnalc $^{+/+}: n=5$; Cacnalc $^{+/-}: n=7$; Data presented as means \pm SEM. $* p<$ 0.05 , Student's $t$ test (colour figure online).
A

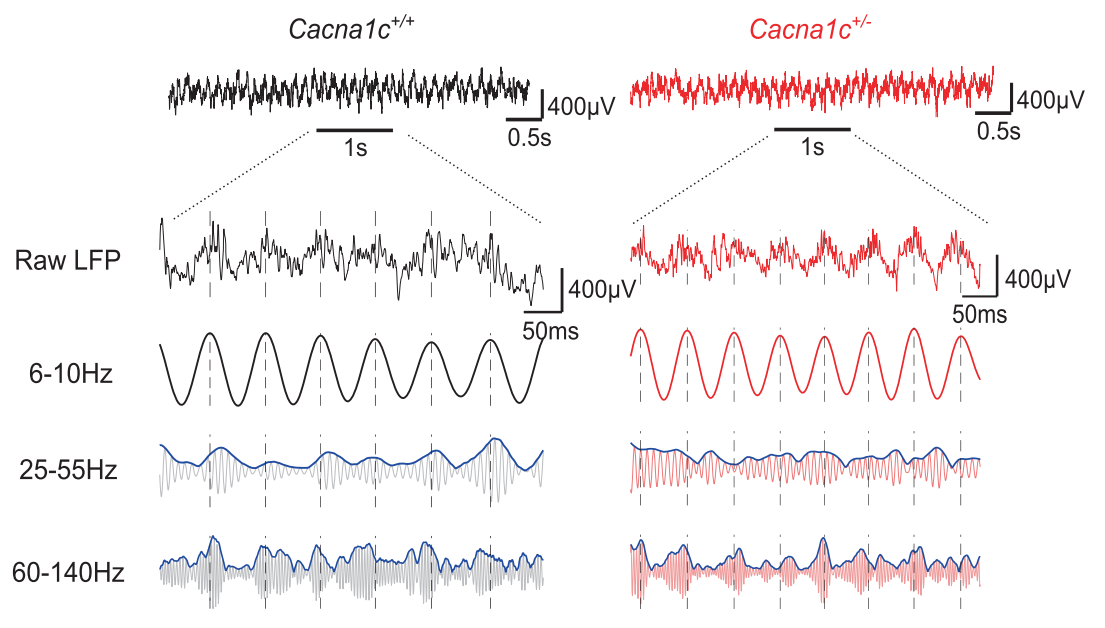

B
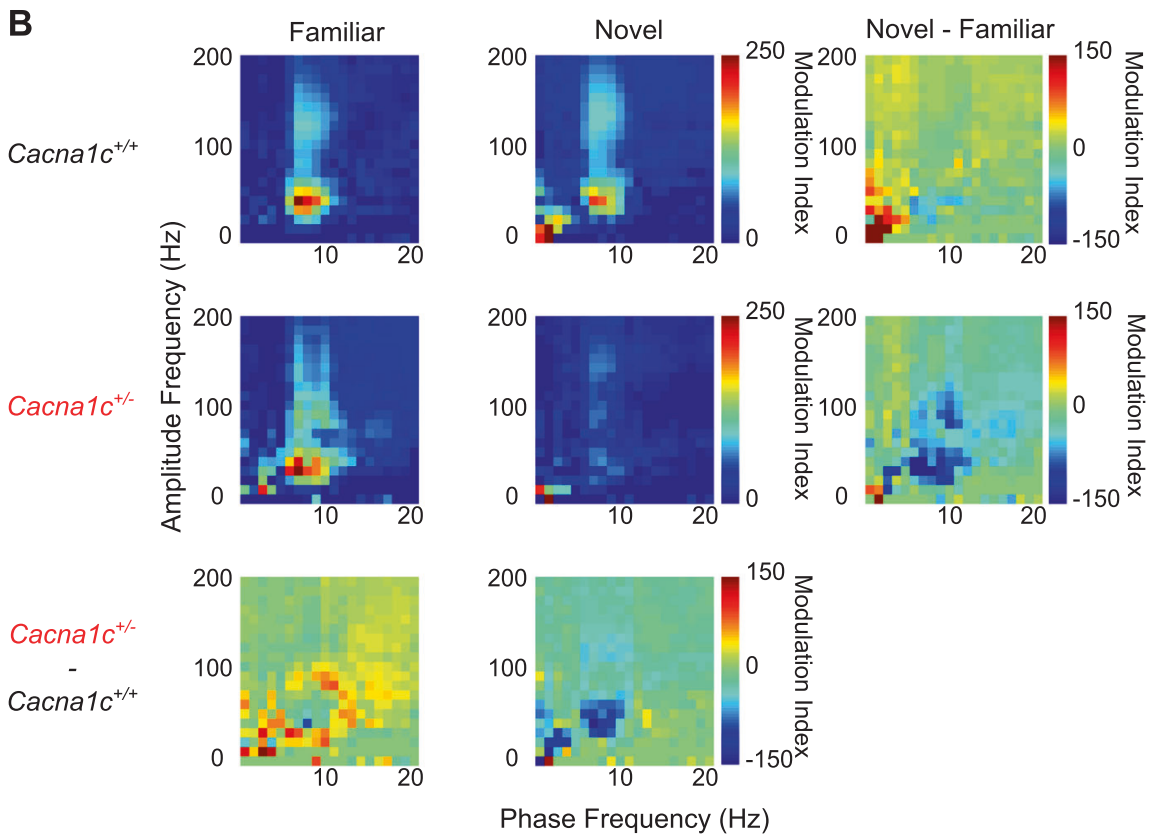

C
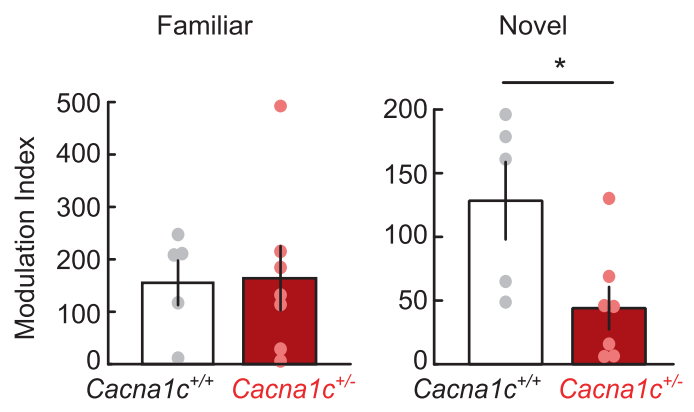

LM22B-10 $60 \mathrm{~min}$ before the pre-exposure stage of LI training rescued the LI of CFC in Cacnalc $^{+/-}$animals tested $24 \mathrm{~h}, 7$ days and 21 days after CFC training (Fig. 5G, H). To assess whether intrahippocampal infusion had non-specific confounding effects on hippocampal function, animals received a second $\mathrm{CFC}$ in a separate novel context (context B) in the absence of any infusion, 22 or 23 days later. In the novel context B, animals expressed equivalent levels of freezing responses to context and normal hippocampal-dependent $\mathrm{CFC}$ and fear memory (Fig. 5G, H). LM22B-10 infused rats showed intact and context-specific LI of CFC when returned to the 


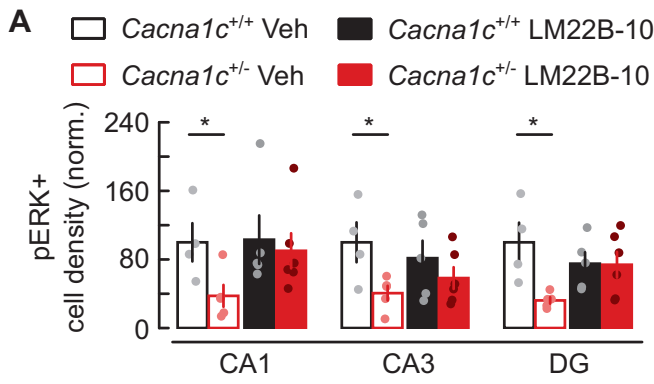

B
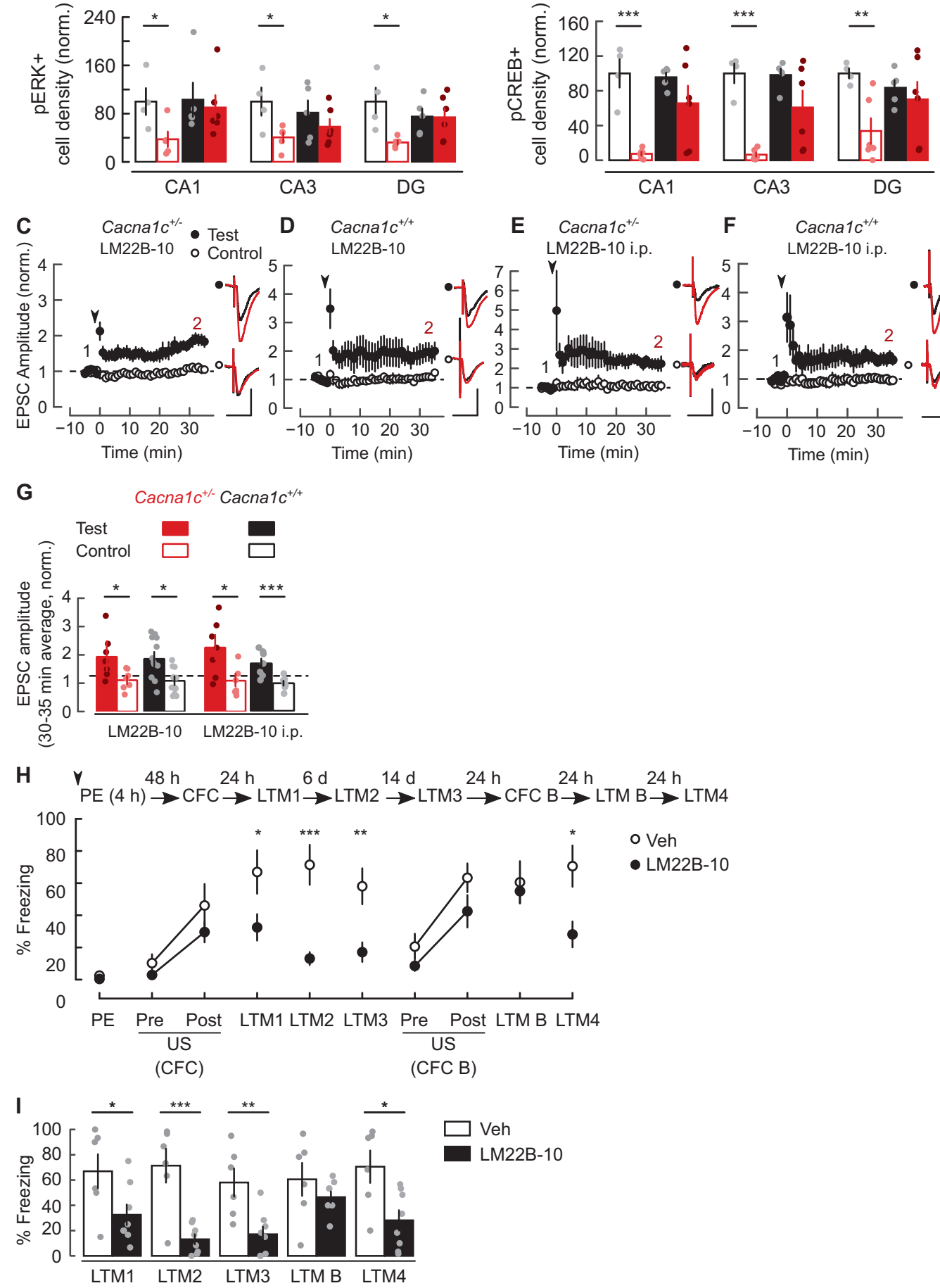

original conditioned context at LTM4 (Fig. 5G, H). Therefore, intrahippocampal infusion of LM22B-10 rescued LI without deleterious effects on hippocampal function. In a separate cohort of $\mathrm{Cacnalc}^{+/-}$rats, intraperitoneal injection of LM22B-10 throughout the LI procedure also rescued LI of CFC (Fig. S16).
Together, these findings show that activation of the ERK signalling pathway in the dorsal hippocampus during LI pre-exposure is sufficient to rescue the behavioural deficits seen in Cacnalc $^{+/-}$rats. This effect can be achieved with both intrahippocampal administration of LM22B-10 and with systemic dosing. 
Fig. 5 The TrkB/TrkC receptor agonist LM22B-10 rescued dorsal hippocampal ERK-CREB signalling, synaptic plasticity, and LI of CFC in Cacnalc $^{+-}$rats. Systemic administration of the TrkB/TrkC agonist LM22B-10 (25 mg/kg, i.p.) restored the baseline levels of pERK (A) and pCREB (B) in dorsal hippocampus of Cacnalc $^{+-}$rats; pERK genotype $\times$ treatment: $F_{(1,16)}=4.567, p=0.048$; genotype effect, vehicle-treated (Veh): $F_{(1,16)}=12.866, p=0.002$; LM22B-10treated: $F_{(1,16)}=0.615, p=0.444 ; \quad$ pCREB genotype $\times$ treatment: $F_{(1,17)}=5.239, p=0.035$; genotype effect, Veh: $F_{(1,16)}=21.319, p=$ 0.000 , and LM22B-10: $F_{(1,16)}=2.485, p=0.133$. There was no significant treatment effect in Cacnalc ${ }^{+/+}$animals (pERK: $\mathrm{F}_{(1,21)}=0.54$, $p=0.47$; pCREB: $\left.F_{(1,21)}=0.98, p=0.33\right)$. Bars represent summary of immunopositive cell densities in CA1, CA3 and dentate gyrus (DG) of dorsal hippocampus, normalized to average Cacnalc $^{+/+}$values. Examples of immunoreactive sections are shown in Fig. S14. Animals were sacrificed $60 \mathrm{~min}$ after i.p. administration of drug or vehicle and processed for both ERK and CREB; sample sizes for $\mathrm{Cacnalc}^{+/+}$: LM22B-10 $n=5$, Veh $n=4$; Cacnalc $^{+/-}$: LM22B-10 $n=6$, Veh $n=5$ (pERK) and $n=6$ (pCREB). C-G LM22B-10 rescued SC-CA1 LTP induction with TBP in slices from Cacnalc $^{+/-}$rats, either during bath application $(2 \mu \mathrm{M}, \mathrm{C})$ or after i.p. bolus $(25 \mathrm{mg} / \mathrm{kg}$, E). LM22B-10 had no effect on TBP-induced SC-CA1 LTP in wild-type slices, either during bath application (D) or after i.p. bolus $(\mathbf{F})$. Insets: 5 min average EPSC waveforms before (1, black) and 30-35 min after (2, red) LTP induction; scale bars: $50 \mathrm{pA}, 50 \mathrm{~ms}$. G Summary of change in normalized mean EPSC amplitude at 30-35 min after LTP in (C-F). Pairwise test vs control, C $p=0.034, n=12(4)$; D $p=0.032, n=7$ (4); $\mathbf{E} p=0.044, n=7(4) ; \mathbf{F} p=0.008, n=7(5)$; sample sizes given as cells(animals). H Intrahippocampal infusion of LM22B-10 before context pre-exposure rescued LI of CFC in Cacnalc $^{+/-}$animals. Schematic: behavioural paradigm in Fig. S1 extended with memory retrieval trials in LI context (LTM3, LTM4), alternative context training (CFC B) and retrieval (LTM B). Arrowhead: bilateral infusion of $1 \mu \mathrm{L}$ LM22B-10 $(2 \mu \mathrm{M}, n=8)$ or vehicle (Veh, $n=6)$ in dorsal hippocampus $60 \mathrm{~min}$ before $\mathrm{PE}$. The plot shows the freezing response in all sessions. I Summary of freezing response at LTM trials. The freezing responses in LM22B-10 and Veh groups were different (treatment $\times$ stage: $F_{(5,60)}=5.205, p=0.002$ ). Compared to the vehicle group, LM22B-10 animals showed reduced freezing responses only in the LI context (between-subject contrasts vs Veh, LTM1: $F_{(1,11)}=$ 4.162, $p=0.033$, LTM2: $F_{(1,11)}=18.467, p=0.0005$, LTM3: $F_{(1,11)}=9.602, p=0.005$, LTM4: $\mathrm{F}_{(1,11)}=6.886, p=0.012$, LTM B: $\left.F_{(1,11)}=0.138, p=0.358\right)$. All data are presented as means \pm SEM. $* p<0.05, * * p<0.01$ and $* * * p<0.001$, two-way repeated measures ANOVA then pairwise post-hoc comparison with Bonferroni correction $(\mathbf{A}, \mathbf{B}, \mathbf{G}, \mathbf{H})$ and two-way ordinal regression (ANODE) then Tukey-adjusted post-hoc comparisons (colour figure online).

\section{Discussion}

Advances in psychiatric genomics have consistently revealed association of schizophrenia, bipolar disorder and related neurodevelopmental disorders with genetic variation in VGCCs and in particular CACNAIC. Understanding the impact of genetic variation in the associated loci is critical for gaining mechanistic insight into these conditions and development of new therapies.

Psychotic symptoms pathognomonic of schizophrenia and frequent in bipolar disorder have been associated with altered learning about associations between environmental stimuli [18-20], leading to aberrant attribution of importance (or salience) to irrelevant events [36]. This aberrant learning can be objectivized by the LI procedure, which requires hippocampal and mesolimbic dopaminergic functional integrity $[18,37]$ and is affected in psychosis [17]. Consistent with impairments seen in psychotic patients, we found that low dosage of Cacnalc produced a marked deficit in contextual LI despite normal contextual fear conditioning. Our observations agree with previous studies of homozygous deletions of Cacnalc or Cacnald (encoding the pore-forming subunits of $\mathrm{Ca}_{\mathrm{V}} 1.2$ and $\mathrm{Ca}_{\mathrm{V}} 1.3 \mathrm{~L}$-VGCCs, respectively) showing that $\mathrm{Ca}_{\mathrm{V}} 1.3$, but not $\mathrm{Ca}_{\mathrm{V}} 1.2$, is essential for acquisition of fear associations [35, 62]. Together with evidence from brain-specific knock-out studies $[24,63]$ our findings support a requirement for $\mathrm{Ca}_{\mathrm{V}} 1.2$, but not $\mathrm{Ca}_{\mathrm{v}} 1.3$, in context discrimination. The disruption of $\mathrm{LI}$ in wild-type animals and rescue in Cacnalc $^{+/-}$littermates by intrahippocampal drugs implicates the hippocampus as a major lesion site in our model. Therefore, hippocampal encoding of contextual information needed for LI may be particularly susceptible to alterations in Cacnalc dosage. Further studies are needed into potential upstream changes and the impact of this hippocampal dysfunction on mesolimbic dopamine signalling [16, 64] in our model.

Formation of novel context representations in the hippocampus involves synaptic LTP at excitatory afferents from $\mathrm{EC}$ and CA3 area during theta-burst firing [53]. We hypothesized that the low $\mathrm{Ca}_{\mathrm{V}} 1.2$ dosage in $\mathrm{Cacnalc}^{+/-}$rats impacts on both LTP and the coordination of synaptic activity in CA1. Associative LTP is induced during thetaburst firing (TBP-LTP) by temporally coordinated pre- and postsynaptic neuronal activity and the activation of postsynaptic NMDARs and VGCCs [25, 26, 44]. In Cacnalc ${ }^{+-}$ animals, TBP-LTP was impaired at SC-CA1 pathway although SC-CA1 synapses are capable of L-VGCCindependent LTP. This distinction mitigates against spine abnormalities as principal cause for the plasticity deficit.

To understand the causes of the SC-CA1 TBP-LTP deficit we investigated excitability and spine calcium signalling in Cacnalc $^{+/-}$CA1 pyramidal neurons. Cacnalc ${ }^{+-}$ neurons had significantly reduced broadening of somatic APs during theta-burst-like firing, replicated in wild-type cells by L-VGCC block with isradipine, confirming a role for L-VGCCs. Consistent with weaker dendritic $\mathrm{Ca}^{2+}$ signals elicited by narrower APs [51] we observed inefficient summation of spine $\mathrm{Ca}^{2+}$ signals at SC-CA1 synapses during AP bursts in Cacnalc ${ }^{+-}$neurons. Our findings reveal a mechanism by which Cacnalc hemizygosity causes inadequate AP-triggered spine $\mathrm{Ca}^{2+}$ signalling disrupting the pre- and postsynaptic spiking association necessary for LTP [26]. A necessary pharmacological dissection of the relative contributions of $\mathrm{Ca}_{\mathrm{V}} 1.2$ and $\mathrm{Ca}_{\mathrm{V}} 1.3$ in these processes depends on the advent of isoform-selective antagonists, which are not yet available [33]. 
In Cacnalc $^{+/-}$animals TBP-LTP was preserved at the other major excitatory input, TA-CA1. This dissociation suggests that Cacnalc hemizygosity does not affect L-VGCC-dependent mechanisms in distal dendrites, where local spiking is more important for LTP [25]. Our results suggest an impaired processing of conjunctive EC and CA3 inputs to CA1 leading to altered novel context representations in Cacnalc ${ }^{+/-}$animals.

Network synchronization in CA1 may contribute to the establishment of hippocampal memory traces by providing adequate temporal coordination between pre- and postsynaptic spiking [21]. PAC between CA1 theta and slowgamma oscillations in Cacnalc ${ }^{+/-}$rats was reduced specifically during exploration of a novel environment, indicating a mis-coupling between CA1 neurons and excitatory input from CA3 [55]. Theta-gamma PAC alterations across brain regions observed in animal models of psychosis [65] and schizophrenic patients [66], may reflect wider network deficits in psychoses.

One behavioural consequence of low Cacnalc dosage is a contextual LI deficit. Nevertheless, Cacnalc $c^{+/-}$rats are apparently able to form contextual fear memories. This suggests that the ability to form context representations or associative contextual memory-an event or non-event in the context-is altered but not absent in our model. The successful retrieval and behavioural expression of such memories depends on reactivation of firing activity in distinct sparse hippocampal neuronal ensembles or engrams formed during learning $[67,68]$. Altered engram formation may impair engram indexing function $[68,69]$, which may normally contribute to retrieval of the context-no event memory during conditioning, or retrieval of a specific memory during recall.

At molecular level, L-VGCC-mediated $\mathrm{Ca}^{2+}$ signalling imparts location and temporal specificity for excitation-transcription coupling and activation of ERK signalling [29, 30]. ERK is necessary for early [27, 28] and late, protein synthesis dependent, LTP and memory [70]. We found a markedly decreased activation of ERK and CREB in Cacnalc ${ }^{+/-}$hippocampi, despite unchanged hippocampal cytoarchitecture [3].

Taken together our results show that Cacnalc hemizygosity impairs hippocampal function and ERK signallingmediated excitation-transcription coupling likely to result in behavioural deficits observed in Cacnalc $^{+/-}$animals. Our findings implicate constitutively dysregulated Cacnalc expression in psychiatric risk, in line with altered cognitive functions and synaptic plasticity following embryonic ablation of Cacnalc in glutamatergic neurons [71]. An important future aim is to determine with greater confidence the contribution of specific cell types to these phenotypes.

Recent studies support the targeting of neurotrophin receptors using small-molecule BDNF mimetics as potential therapeutic strategy in neuropsychiatric and neurodegenerative disorders $[72,73]$. We tested the effects of the smallmolecule TrkB/TrkC co-activator LM22B-10 with BDNF mimetic activity in vivo [61]. In Cacnalc $^{+/-}$animals, direct application of LM22B-10 on hippocampal slices rescued synaptic plasticity, as predicted by ERK's role in earlyphase LTP [27, 28, 74]. Hippocampal infusion of LM22B10 during context pre-exposure was sufficient to rescue LI, suggesting that context representations formed during preexposure are stable without requiring ongoing treatment. Systemic treatment with LM22B-10 rescued hippocampal molecular and plasticity changes and restored normal LI behaviour in Cacnalc ${ }^{+/-}$rats. Future work will focus on effects of LM22B-10 on network activity in vivo, not addressed in this study, and translational biomarkers as provided by brain imaging.

In conclusion, by adopting a genomically informed approach to investigate pathological processes associated with genetic risk for neuropsychiatric disorders we show that Cacnalc hemizygosity impairs selective forms of associative learning, hippocampal synaptic plasticity, network synchronization, and ERK signalling-mediated excitation-transcription coupling. In addition, our work supports investigating the potential benefit of drugs targeting neurotrophin receptor signalling in psychiatric disorders.

Acknowledgements We thank J Carter, I Morella and C Best for technical support. We thank Prof. JR Mellor and Prof. R Brambilla for helpful discussions.

Author contributions CMT, TEL, LS, MCO, MJO., LSW, ERM, MWJ, KLT and JH designed the experiments and analyses, and wrote the manuscript. TEL, LS and KLT performed behavioural experiments. CMT performed ex vivo electrophysiology and imaging experiments. ERM performed in vivo electrophysiology experiments. TEL, ALM and KLT performed the molecular studies.

Funding This work was supported by MRC grants no. MR/R011397/1 (JH, KLT, LSW) and MR/L010305/1 (MJO, JH, LSW, MCO), Wellcome Trust grants 100202/Z/12/Z (CMT, ERM, MJO, JH, LSW, MWJ) and 099821/Z/12/Z (LS), 'Wellcome Senior Research Fellowship in Basic Biomedical Science' 202810/Z/16/Z (MWJ), and support from The Waterloo Foundation Changing Minds Programme.

\section{Compliance with ethical standards}

Conflict of interest The authors declare that they have no conflict of interest.

Publisher's note Springer Nature remains neutral with regard to jurisdictional claims in published maps and institutional affiliations.

Open Access This article is licensed under a Creative Commons Attribution 4.0 International License, which permits use, sharing, adaptation, distribution and reproduction in any medium or format, as long as you give appropriate credit to the original author(s) and the 
source, provide a link to the Creative Commons license, and indicate if changes were made. The images or other third party material in this article are included in the article's Creative Commons license, unless indicated otherwise in a credit line to the material. If material is not included in the article's Creative Commons license and your intended use is not permitted by statutory regulation or exceeds the permitted use, you will need to obtain permission directly from the copyright holder. To view a copy of this license, visit http://creativecommons. org/licenses/by/4.0/.

\section{References}

1. International Schizophrenia Consortium, Purcell SM, Wray NR, Stone JL, Visscher PM, O'Donovan MC, et al. Common polygenic variation contributes to risk of schizophrenia and bipolar disorder. Nature. 2009;460:748-52.

2. Birnbaum R, Weinberger DR. Special Article: Translational Science Update. Pharmacological Implications of Emerging Schizophrenia Genetics: Can the Bridge From 'Genomics' to 'Therapeutics' be Defined and Traversed? J Clin Psychopharmacol. 2020;40:323-9.

3. Moon AL, Haan N, Wilkinson LS, Thomas KL, Hall J. CACNA1C: Association With Psychiatric Disorders, Behavior, and Neurogenesis. Schizophrenia Bull. 2018;44:958-65.

4. Pardiñas AF, Holmans P, Pocklington AJ, Escott-Price V, Ripke $\mathrm{S}$, Carrera N, et al. Common schizophrenia alleles are enriched in mutation-intolerant genes and in regions under strong background selection. Nat Genet. 2018;50:381-9.

5. Stahl EA, Breen G, Forstner AJ, McQuillin A, Ripke S, Trubetskoy $\mathrm{V}$, et al. Genome-wide association study identifies 30 loci associated with bipolar disorder. Nat Genet. 2019;51:793-803.

6. Bigos KL, Mattay VS, Callicott JH, Straub RE, Vakkalanka R, Kolachana B, et al. Genetic variation in CACNA1C affects brain circuitries related to mental illness. Arch Gen Psychiatry. 2010;67:939-45.

7. Roussos P, Mitchell AC, Voloudakis G, Fullard JF, Pothula VM, Tsang J, et al. A role for noncoding variation in schizophrenia. Cell Rep. 2014;9:1417-29.

8. Yoshimizu T, Pan JQ, Mungenast AE, Madison JM, Su S, Ketterman J, et al. Functional implications of a psychiatric risk variant within CACNA1C in induced human neurons. Mol Psychiatry. 2015;20:162-9.

9. Eckart N, Song Q, Yang R, Wang R, Zhu H, McCallion AS, et al. Functional Characterization of Schizophrenia-Associated Variation in CACNA1C. PLoS ONE. 2016;11:e0157086.

10. Jaffe AE, Hoeppner DJ, Saito T, Blanpain L, Ukaigwe J, Burke EE, et al. Profiling gene expression in the human dentate gyrus granule cell layer reveals insights into schizophrenia and its genetic risk. Nat Neurosci. 2020;23:510-9.

11. Purcell SM, Moran JL, Fromer M, Ruderfer D, Solovieff N, Roussos $\mathrm{P}$, et al. A polygenic burden of rare disruptive mutations in schizophrenia. Nature. 2014;506:185-90.

12. Kaplanis J, Samocha KE, Wiel L, Zhang Z, Arvai KJ, Eberhardt $\mathrm{RY}$, et al. Evidence for 28 genetic disorders discovered by combining healthcare and research data. Nature. 2020; 586:757-62.

13. Obermair GJ, Szabo Z, Bourinet E, Flucher BE. Differential targeting of the L-type $\mathrm{Ca}^{2+}$ channel alpha $1 \mathrm{C}(\mathrm{CaV} 1.2)$ to synaptic and extrasynaptic compartments in hippocampal neurons. Eur $\mathbf{J}$ Neurosci. 2004;19:2109-22.

14. Harrison PJ. The hippocampus in schizophrenia: a review of the neuropathological evidence and its pathophysiological implications. Psychopharmacology. 2004;174:151-62.
15. Frey BN, Andreazza AC, Nery FG, Martins MR, Quevedo J, Soares JC, et al. The role of hippocampus in the pathophysiology of bipolar disorder. Behav. Pharmacol. 2007;18:419-30.

16. Lodge DJ, Grace AA. Hippocampal dysregulation of dopamine system function and the pathophysiology of schizophrenia. Trends Pharmacol Sci. 2011;32:507-13.

17. Lubow RE, Weiner I, Schlossberg A, Baruch I. Latent inhibition and schizophrenia. Bull Psychonomic Soc. 1987;25:464-7.

18. Gray JA. Integrating schizophrenia. Schizophr Bull. 1998;24:249-66.

19. Hemsley DR. The development of a cognitive model of schizophrenia: placing it in context. Neurosci Biobehav Rev. 2005;29:977-88

20. Reilly JL, Hill SK, Gold JM, Keefe RS, Clementz BA, Gershon E, et al. Impaired Context Processing is Attributable to Global Neuropsychological Impairment in Schizophrenia and Psychotic Bipolar Disorder. Schizophr Bull. 2017;43:397-406.

21. Fell J, Axmacher N. The role of phase synchronization in memory processes. Nat Rev Neurosci. 2011;12:105-18.

22. Lisman JE, Jensen O. The theta-gamma neural code. Neuron. 2013;77:1002-16.

23. Takeuchi T, Duszkiewicz AJ, Morris RG. The synaptic plasticity and memory hypothesis: encoding, storage and persistence. Philos Trans R Soc Lond B Biol Sci. 2014;369:20130288.

24. Moosmang S, Haider N, Klugbauer N, Adelsberger H, Langwieser N, Müller J, et al. Role of hippocampal Cav1.2 $\mathrm{Ca}^{2+}$ channels in NMDA receptor-independent synaptic plasticity and spatial memory. J Neurosci. 2005;25:9883-92.

25. Kim Y, Hsu C-L, Cembrowski MS, Mensh BD, Spruston N. Dendritic sodium spikes are required for long-term potentiation at distal synapses on hippocampal pyramidal neurons. eLife. 2015;4: e06414.1.

26. Tigaret CM, Olivo V, Sadowski J, Ashby MC, Mellor JR. Coordinated activation of distinct $\mathrm{Ca}(2+)$ sources and metabotropic glutamate receptors encodes Hebbian synaptic plasticity. Nat Commun. 2016;7:10289.

27. Winder DG, Martin KC, Muzzio IA, Rohrer D, Chruscinski A, Kobilka B, et al. ERK plays a regulatory role in induction of LTP by theta frequency stimulation and its modulation by betaadrenergic receptors. Neuron. 1999;24:715-26.

28. Patterson MA, Szatmari EM, Yasuda R. AMPA receptors are exocytosed in stimulated spines and adjacent dendrites in a RasERK-dependent manner during long-term potentiation. Proc Natl Acad Sci USA. 2010;107:15951-6.

29. Dolmetsch RE, Pajvani U, Fife K, Spotts JM, Greenberg ME. Signaling to the nucleus by an L-type calcium channel-calmodulin complex through the MAP kinase pathway. Science. 2001;294:333-9.

30. Wheeler DG, Barrett CF, Groth RD, Safa P, Tsien RW. CaMKII locally encodes L-type channel activity to signal to nuclear CREB in excitation-transcription coupling. $\mathrm{J}$ Cell Biol. 2008;183:849-63.

31. Sykes L, Haddon J, Lancaster TM, Sykes A, Azzouni K, Ihssen N, et al. Genetic Variation in the Psychiatric Risk Gene CACNA1C Modulates Reversal Learning Across Species. Schizophr Bull. 2019;45:1024-32.

32. McCutcheon JE, Marinelli M. Age matters. Eur J Neurosci. 2009;29:997-1014.

33. Catterall WA, Perez-Reyes E, Snutch TP, Striessnig J. International Union of Pharmacology. XLVIII. Nomenclature and structure-function relationships of voltage-gated calcium channels. Pharm Rev. 2005;57:411-25.

34. Anagnostaras SG, Gale GD, Fanselow MS. Hippocampus and contextual fear conditioning: recent controversies and advances. Hippocampus. 2001;11:8-17. 
35. McKinney BC, Sze W, White JA, Murphy GG. L-type voltagegated calcium channels in conditioned fear: a genetic and pharmacological analysis. Learn Mem. 2008;15:326-34.

36. Kapur S. Psychosis as a state of aberrant salience: a framework linking biology, phenomenology, and pharmacology in schizophrenia. Am J Psychiatry. 2003;160:13-23.

37. Holt W, Maren S. Muscimol inactivation of the dorsal hippocampus impairs contextual retrieval of fear memory. J Neurosci. 1999;19:9054-62.

38. Matsuo N, Reijmers L, Mayford M. Spine-type-specific recruitment of newly synthesized AMPA receptors with learning. Science. 2008;319:1104-7.

39. Nakashiba T, Young JZ, McHugh TJ, Buhl DL, Tonegawa S. Transgenic inhibition of synaptic transmission reveals role of CA3 output in hippocampal learning. Science. 2008;319:1260-4.

40. Cohen JD, Bolstad M, Lee AK. Experience-dependent shaping of hippocampal CA1 intracellular activity in novel and familiar environments. Elife. 2017;6:e23040.

41. Remondes M, Schuman EM. Role for a cortical input to hippocampal area CA1 in the consolidation of a long-term memory. Nature. 2004;431:699-703.

42. Buzsaki G, Penttonen M, Nadasdy Z, Bragin A. Pattern and inhibition-dependent invasion of pyramidal cell dendrites by fast spikes in the hippocampus in vivo. Proc Natl Acad Sci USA. 1996;93:9921-5.

43. Larson J, Munkácsy E. Theta-burst LTP. Brain Res. 2015;1621:38-50.

44. Magee JC, Johnston D. A synaptically controlled, associative signal for Hebbian plasticity in hippocampal neurons. Science. 1997;275:209-13.

45. Perkel DJ, Petrozzino JJ, Nicoll RA, Connor JA. The role of $\mathrm{Ca}^{2+}$ entry via synaptically activated NMDA receptors in the induction of long-term potentiation. Neuron. 1993;11:817-23.

46. Kim J, Wei DS, Hoffman DA. Kv4 potassium channel subunits control action potential repolarization and frequency-dependent broadening in rat hippocampal CA1 pyramidal neurones. J Physiol. 2005;569:41-57.

47. Shao LR, Halvorsrud R, Borg-Graham L, Storm JF. The role of BK-type $\mathrm{Ca}^{2+}$-dependent $\mathrm{K}+$ channels in spike broadening during repetitive firing in rat hippocampal pyramidal cells. J Physiol. 1999;521:135-46.

48. Berkefeld H, Sailer CA, Bildl W, Rohde V, Thumfart JO, Eble S, et al. BKCa-Cav channel complexes mediate rapid and localized $\mathrm{Ca}^{2+}$-activated $\mathrm{K}+$ signaling. Science. 2006;314:615-20.

49. Berkefeld H, Fakler B. Repolarizing responses of BKCa-Cav complexes are distinctly shaped by their Cav subunits. J Neurosci. 2008;28:8238-45.

50. Golding NL, Kath WL, Spruston N. Dichotomy of actionpotential backpropagation in CA1 pyramidal neuron dendrites. J Neurophysiol. 2001;86:2998-3010.

51. Bloodgood BL, Sabatini BL. Nonlinear regulation of unitary synaptic signals by $\mathrm{CaV}(2.3)$ voltage-sensitive calcium channels located in dendritic spines. Neuron. 2007;53:249-60.

52. Leitch B, Szostek A, Lin R, Shevtsova O. Subcellular distribution of L-type calcium channel subtypes in rat hippocampal neurons. Neuroscience. 2009;164:641-57.

53. Hasselmo ME, Bodelon C, Wyble BP. A proposed function for hippocampal theta rhythm: separate phases of encoding and retrieval enhance reversal of prior learning. Neural Comput. 2002;14:793-817.

54. Kitanishi T, Ujita S, Fallahnezhad M, Kitanishi N, Ikegaya Y, Tashiro A. Novelty-Induced Phase-Locked Firing to Slow Gamma Oscillations in the Hippocampus: Requirement of Synaptic Plasticity. Neuron. 2015;86:1265-76.
55. Colgin LL. Theta-gamma coupling in the entorhinal-hippocampal system. Curr Opin Neurobiol. 2015;31:45-50.

56. Fernandez-Ruiz A, Oliva A, Nagy GA, Maurer AP, Berenyi A, Buzsaki G. Entorhinal-CA3 Dual-Input Control of Spike Timing in the Hippocampus by Theta-Gamma Coupling. Neuron. 2017;93:1213-26 e5.

57. Colgin LL, Denninger T, Fyhn M, Hafting T, Bonnevie T, Jensen $\mathrm{O}$, et al. Frequency of gamma oscillations routes flow of information in the hippocampus. Nature. 2009;462:353-7.

58. Ahmed OJ, Mehta MR. Running speed alters the frequency of hippocampal gamma oscillations. J Neurosci. 2012;32:7373-83.

59. Richard GR, Titiz A, Tyler A, Holmes GL, Scott RC, LenckSantini PP. Speed modulation of hippocampal theta frequency correlates with spatial memory performance. Hippocampus. 2013;23:1269-79.

60. Sheremet A, Kennedy JP, Qin Y, Zhou Y, Lovett SD, Burke SN, et al. Theta-gamma cascades and running speed. J Neurophysiol. 2019;121:444-58.

61. Yang T, Massa SM, Tran KC, Simmons DA, Rajadas J, Zeng AY, et al. A small molecule TrkB/TrkC neurotrophin receptor coactivator with distinctive effects on neuronal survival and process outgrowth. Neuropharmacology. 2016;110:343-61.

62. McKinney BC, Murphy GG. The L-Type voltage-gated calcium channel Cav1.3 mediates consolidation, but not extinction, of contextually conditioned fear in mice. Learn Mem. 2006;13:584-9.

63. Temme SJ, Bell RZ, Fisher GL, Murphy GG. Deletion of the Mouse Homolog of CACNA1C Disrupts Discrete Forms of Hippocampal-Dependent Memory and Neurogenesis within the Dentate Gyrus. eNeuro. 2016;3:ENEURO.0118-16.2016.

64. Terrillion CE, Dao DT, Cachope R, Lobo MK, Puche AC, Cheer $\mathrm{JF}$, et al. Reduced levels of Cacna1c attenuate mesolimbic dopamine system function. Genes Brain Behav. 2017;16:495-505.

65. Kalweit AN, Amanpour-Gharaei B, Colitti-Klausnitzer J, Manahan-Vaughan D. Changes in Neuronal Oscillations Accompany the Loss of Hippocampal LTP that Occurs in an Animal Model of Psychosis. Front Behav Neurosci. 2017;11:36.

66. Won GH, Kim JW, Choi TY, Lee YS, Min KJ, Seol KH. Thetaphase gamma-amplitude coupling as a neurophysiological marker in neuroleptic-naïve schizophrenia. Psychiatry Res. 2018;260:406-11.

67. Cai DJ, Aharoni D, Shuman T, Shobe J, Biane J, Song W, et al. A shared neural ensemble links distinct contextual memories encoded close in time. Nature. 2016;534:115-8.

68. Tanaka KZ, McHugh TJ. The Hippocampal Engram as a Memory Index. J Exp Neurosci. 2018;12:1179069518815942.

69. Teyler TJ, DiScenna P. The hippocampal memory indexing theory. Behav Neurosci. 1986;100:147-54.

70. Chwang WB, O'Riordan KJ, Levenson JM, Sweatt JD. ERK/ MAPK regulates hippocampal histone phosphorylation following contextual fear conditioning. Learn Mem. 2006;13:322-8.

71. Dedic N, Pohlmann ML, Richter JS, Mehta D, Czamara D, Metzger MW, et al. Cross-disorder risk gene CACNA1C differentially modulates susceptibility to psychiatric disorders during development and adulthood. Mol Psychiatry. 2018;23:533-43.

72. Autry AE, Monteggia LM. Brain-derived neurotrophic factor and neuropsychiatric disorders. Pharmacol Rev. 2012;64:238-58.

73. Nagahara AH, Tuszynski MH. Potential therapeutic uses of BDNF in neurological and psychiatric disorders. Nat Rev Drug Discov. 2011;10:209-19.

74. Patterson SL, Abel T, Deuel TA, Martin KC, Rose JC, Kandel ER. Recombinant BDNF rescues deficits in basal synaptic transmission and hippocampal LTP in BDNF knockout mice. Neuron. 1996;16:1137-45. 